\title{
ENCONTROS COM O "ENCONTRO DE SABERES"
}

\author{
EdGAR BARBOSA Neto \\ ISABEL SANTANA DE ROSE \\ MARCIO GOLDMAN
}

O presente dossiê é o resultado de duas reuniões do Seminário Temático "Encontro de Saberes: Transversalidades e Experiências" ocorridas respectivamente em 2017 (em São Paulo, na USP) e em 2019 (em Florianópolis, na UFSC), como parte das atividades da VII e da VIII Reunião de Antropologia da Ciência e da Tecnologia (ReACT). A ideia que nos motivou a propor esse seminário temático, de cuja formulação inicial participou o nosso amigo e colega César Guimarães da UFMG, era a de criar um espaço, necessariamente plural, que permitisse um encontro entre alguns dos vários "encontros de saberes". O propósito era constituir um lugar que tornasse possível alguma conexão transversal entre essas diferentes experiências, como uma aposta na direção de seu aprendizado recíproco. Este dossiê retoma o mesmo objetivo do seminário temático.

Necessariamente plural, dissemos, pois isso nos levou a multiplicar o campo de ação mais habitualmente recoberto pela expressão "encontro de saberes". Nem todos os textos apresentados nessas duas reuniões, assim como nem todos os artigos publicados neste dossiê, correspondem exatamente ao que tem sido chamado de "encontro de saberes", que dispõe de um desenho similar nas diferentes universidades nas quais está presente, embora as propostas e arranjos variem de acordo com os contextos locais. Trata-se, em todos esses casos, da inclusão remunerada de mestres e de mestras dos saberes tradicionais como professores e professoras de universidades públicas federais e estaduais. O artigo de José Jorge de Carvalho e Letícia Vianna, que abre este dossiê, recompõe essa história e nos ajuda a situar a singularidade e a importância dessa experiência, desde a sua criação na UnB, em 2010, por iniciativa do próprio José Jorge de Carvalho e como resultado do trabalho do Instituto Nacional de Ciência e Tecnologia de Inclusão no Ensino Superior e na Pesquisa (INCT Inclusão), até o momento atual, no qual assistimos e celebramos a sua expansão para muitas outras universidades.

Essa ampliação do sentido referido pela expressão decorre de uma compreensão, seguramente compartilhada pela maioria dos colegas, de que o encontro de saberes constitui uma dimensão fundamental dos processos de inclusão étnico-raciais criados pelas políticas de ação afirmativa implementadas nos últimos vinte anos pelas universidades brasileiras. Desse modo, a reflexão sobre os encontros de saberes se situa dentro de um processo mais amplo de transformação das universidades, no qual, entre outros fatores, tem destaque um ingresso cada vez maior de estudantes negros(as) e indígenas na graduação e 
na pós-graduação. Todos esses processos, na própria heterogeneidade de sua existência, constituem, como escrevem José Jorge de Carvalho e Letícia Vianna, "intervenções no mundo acadêmico em várias dimensões: de inclusão étnico-racial, política, pedagógica, institucional/administrativa e epistêmica". O encontro de saberes, na sua acepção mais específica, nos obrigou a olhar para todas essas intervenções como experiências que criam diferentes situações de encontro. Nesse sentido, as experiências de encontros de saberes descritas nos textos reunidos neste dossiê englobam, além da presença dos mestres e mestras dos saberes tradicionais nas universidades, programas de pós graduação interculturais especificamente voltados para os povos e comunidades tradicionais; licenciaturas interculturais indígenas; pesquisas etnográficas realizadas com comunidades que circulam pelos espaços universitários e que estabelecem relações, alianças e limites com os conhecimentos acadêmicos; reflexões sobre o registro audiovisual dessas experiências e os aspectos éticos envolvidos, entre outras questões.

O modo de existência de um encontro cria várias obrigações para o lado majoritário e hegemônico que o compõe. Estamos pensando no meio acadêmico, ao qual estamos vinculados, e nas diversas formas pelas quais as intervenções acima são capazes de interpelálo. Os vários artigos aqui publicados são testemunhos de como as políticas de inclusão epistêmica e étnico-racial são capazes de criar processos heterogêneos de transformação. Esses processos se aglutinam em pelo menos duas dimensões, que nos parecem diferentes e, no entanto, indissociáveis. Trata-se, por um lado, de transformações propriamente institucionais, com a necessária criação de meios administrativos e jurídicos capazes de responder às exigências constituídas pela presença de saberes, de corpos e de coletivos historicamente excluídos da universidade. Por outro, trata-se da recriação dos meios pedagógicos, da abertura de outras possibilidades para as práticas de pesquisa e de extensão, mas também para as práticas de ensino, ou seja, para o que pode ser, por exemplo, uma aula quando passa a existir diante de tempos, lugares, técnicas e relações necessariamente mais plurais, com efeitos modificativos sobre os procedimentos de avaliação e, principalmente, sobre o seu sentido. Uma aula, em muitos desses casos, se vê povoada por forças não exclusivamente humanas, vinculadas a esses saberes, corpos e coletivos, e que dispõem de um lugar fundamental nas cosmologias afro-brasileiras e indígenas. Essas duas dimensões confluem na afirmação de valores alternativos àqueles estabelecidos pela ecologia neoliberal, que hegemoniza a relação entre as práticas acadêmicas. Contra a concorrência e a produtividade, que desmembram as experiências de criação e inoculam as mais diferentes práticas com seus venenos racistas e colonialistas, surgem então outras possibilidades de pensamento conjunto, de uma inteligência coletiva transversal. 
A palavra encontro é uma daquelas que precisamos aprender a cultivar, pois pensamos que ela pode ser recebida de forma excessivamente cômoda, ou mesmo de modo romântico ou exótico, como se a experiência que ela designa pudesse ser fácil demais. Acreditamos que um encontro possa ser caracterizado de uma maneira ecológica, no sentido que Isabelle Stengers (2005) dá a esta noção. O que uma experiência de encontro coloca em relação são práticas heterogêneas, as quais não podem usar o encontro para abstrair ou negligenciar essa heterogeneidade. Em outras palavras, em um encontro de saberes, ninguém, a rigor, pode falar em seu nome, pois, na medida em que há um encontro, não existe posição que permita totalizar o seu sentido. Os diversos textos que fazem parte deste dossiê demonstram que não há uma única história a contar sobre essa experiência.

Mesmo um movimento que todos nós afirmamos como importante, e que sempre será preciso afirmar como importante, não é invulnerável a certos perigos aos quais o meio acadêmico expõe todos aqueles que, de maneiras muito variadas, entram em relação com ele. Um encontro tem vários lados, e alguns deles podem ter motivos muito consistentes para hesitar diante daquele que está justamente provendo os meios (lugares, logística, dinheiro) para o encontro, no caso, claro, o lado acadêmico. Em um exercício de ficção, poderíamos perfeitamente nos imaginar interpelados por uma questão do seguinte tipo: "o que essas pessoas, esses acadêmicos, mais uma vez, querem comigo? Por que esse interesse"? Capitã Pedrina dos Santos e Makota Kidoiale, ambas professoras da Formação Transversal em Saberes Tradicionais da UFMG (FT Saberes Tradicionais), sugerem que esse interesse pode estar relacionado com o fato de que inventamos uma doença da qual já não sabemos mais como nos curar. A própria impotência seria parte dessa doença, a "doença dos colonialistas", como afirma Antônio Bispo dos Santos (2019), mestre quilombola que também foi professor nessa Formação Transversal.

Mas, voltemos à pergunta imaginada: "esse povo que sempre dividiu o mundo entre aqueles que sabem e aqueles que acreditam, entre a ciência e a não ciência, descobriu que essa divisão pode ter a ver com essa sua doença e vem agora pedir a nossa ajuda". Pensamos que pode ser um importante exercício especulativo imaginar o encontro de saberes como uma experiência que coloca à prova exatamente aquelas e aqueles cujas práticas, ainda que muito diversas, sempre contribuíram para dividir o mundo.

Isabelle Stengers (2017) abre seu ensaio "Reativar o animismo" ("Reclaiming animism") com uma observação muito importante sobre pessoas que amam dividir e classificar e aquelas que amam fazer pontes, isto é, "tecer relações que transformam uma divisão em um contraste vivo, ativo, com poder de afetar, de produzir pensamento e sentimento" (STENGERS, 2017, p. 2). No entanto, é preciso acrescentar, como faz a autora, que construir pontes "é uma prática situada" (STENGERS, 2017, p. 2). O lado no qual Stengers se situa, a prática filosófica da qual ela se pensa como filha ou herdeira, é precisamente 
aquele responsável pela invenção de muitas divisões. Fazer pontes, portanto, não parece ser exatamente uma tentativa de superar divisões, mas sim, como sustenta Stengers, de fazer essas divisões funcionarem de outra maneira, como um contraste vivo, ativo, não como oposição mortífera.

Um contraste como aquele entre os "saberes orgânicos" e os "saberes sintéticos", tal como elaborado por Bispo dos Santos (2019), nos parece ser um contraste dessa natureza. Poderíamos mesmo dizer que Bispo dos Santos afirma a divisão para aqueles que sempre dividiram e pergunta o que eles (nós?) podem fazer com ela. "Vocês serão capazes de retomar essa divisão como um contraste orgânico e não como um contraste sintético? Ou vocês estão tão doentes que só conseguem imaginar o encontro como uma coisa fácil, como algo pouco exigente?". Caracterizar o encontro de saberes como uma experiência ecológica é resistir à dupla tentação de nos relacionarmos com ele de um modo triunfal ou de um modo crítico (STENGERS, 2003). O que ele requer de nós é provavelmente o que Philippe Pignarre e Isabelle Stengers (2005) denominam atenção e cuidado (ver também Vièle, 2005).

Pensar-se como situado em um lado da divisão é imaginar que não se está investido de nenhum poder que permita situar a própria divisão. Quem começa achando que não está situado, volta sem perceber para o lugar do qual, no entanto, nunca saiu. Imaginar que não se está situado é supor que o lado no qual nos encontramos nos autorizaria a levá-lo muito rapidamente para todos os outros lados. O que hoje se chama de lugar de fala, na versão que nos parece a mais interessante, é uma espécie de dispositivo político-epistemológico que desautoriza a fala que se pretende de todos os lugares. Essa fala, no modo escrito de sua existência, é precisamente aquela, como a caracteriza Ana Mumbuca, que se quer "neutra", mas que, no entanto, está vinculada a um mundo "no qual é dolorido entrar" (SILVA, 2019, p. 19), um mundo que a confronta com esse "sentimento de incapacidade para juntar as letras" (SILVA, 2019, p. 20).

Um encontro torna sensível e perceptível a experiência de uma fronteira. Em sua dissertação, desenvolvida no Mestrado em Sustentabilidade junto a Povos e Terras Tradicionais da Universidade de Brasília (MESPT/UnB), a respeito do qual trata o artigo de Layla Jorge Teixeira publicado neste dossiê, Ana Mumbuca descreve a universidade como "um lugar fronteiriço e perigoso" no qual o risco que se corre é aquele de ser "seduzido para o estado" (SILVA, 2019, p. 69).

\footnotetext{
"Ao ocupar o espaço do entre lugar, universidade e quilombo, nos dispomos ao lugar fronteiriço. Vez e outra o quilombo precisa saber se estamos cumprindo o ideal, e uma das estratégias é nos reprovar em algum aspecto propositalmente, como teste para saber se permitimos o ego acadêmico estar nos dominando. De forma própria o quilombo faz o controle sobre nós, não permitindo nem nós, nem outros o dominar" (SILVA, 2019, p. 69-70).
}

Para quem está do lado do quilombo, como nos ensina Ana Mumbuca, a percepção do perigo não bloqueia necessariamente o encontro, mas torna difícil pensar diante daquilo 
que ele cria sem sentir o risco que é inseparável dessa própria criação. O presente dossiê, organizado por pessoas situadas no meio acadêmico, afirma o encontro de saberes como uma experiência também capaz de criar outros possíveis para a universidade, uma experiência que nos dá força para resistir à lógica colonialista e neoliberal que se mostra enraizada em suas práticas. Além disso, o dossiê deseja que cada leitora e cada leitor seja capaz de sentir, a partir dos meios de que dispõe e de uma relação necessariamente singular com cada caso, os riscos que sentem muitas daquelas outras pessoas que o encontro conectou. O encontro de saberes talvez seja um encontro porque nenhum saber pode antecipar-se àquilo que o próprio encontro faz acontecer. E isso, sobretudo para aqueles que se conectam com essa experiência pelos seus vínculos com o meio acadêmico, não exige apenas celebração, mas também cuidado.

Por razões de natureza editorial, optamos por publicar o dossiê em duas partes. A primeira delas, lançada agora, contém onze artigos. A segunda, que será publicada no segundo semestre de 2021, contará com nove artigos e uma entrevista. Esse conjunto de textos traduz não apenas a heterogeneidade das experiências às quais se referem, mas também maneiras muito diferentes de realizar a sua abordagem e de pensar a partir das relações estabelecidas com ela. Acreditamos que é de grande interesse que essa variedade possa aparecer e o nosso objetivo foi acolhê-la integralmente nos dois volumes deste dossiê.

O artigo de José Jorge de Carvalho e de Letícia Vianna, que abre o volume, realiza um balanço dos dez primeiros anos do encontro de saberes na universidade, com indicadores que descrevem a sua significativa expansão e com uma reflexão, de natureza mais conceitual, acerca dos termos "mestre" e "mestra" e da figura do "professor parceiro como um anfitrião". Os autores observam que esses indicadores revelam que já dispomos de "um modelo concreto e operacional para efetuarmos a passagem de uma universidade brasileira eurocêntrica, monolíngue, monocultural e monoepistêmica para uma universidade multicultural, poliglota e pluriepistêmica, preparada para incorporar as tradições epistêmicas com que contamos: as ocidentais, orientais, indígenas e as afro-brasileiras". Na sua compreensão, o encontro de saberes seria um exemplo, em uma escala mais reduzida, das transformações almejadas para o conjunto da universidade. Poderíamos dizer que o encontro de saberes, nesse sentido, não seria mais um movimento interno à universidade, mas sim a própria universidade colocada em movimento pela possibilidade muito concreta de refundar o modelo que herdamos do século XX.

Na sequência, os artigos de Ana Flávia Figueiredo e de Layla Teixeira Cesar tratam de dois casos específicos e das várias questões colocadas por cada um deles. O primeiro descreve a experiência de implementação do encontro de saberes na Universidade Federal dos Vales do Jequitinhonha e Mucuri (UFVJM), criada em 2005. O artigo demonstra como a "expansão epistêmica" provocada pelo encontro de saberes é inseparável de processos 
complexos de transformação institucional, o que nos permite compreender como os procedimentos administrativos e as concepções de gestão universitária são afetados pelo trabalho de reorganização pluriepistêmica do saber. A autora descreve ainda a atuação da Comissão Encontro de Saberes, um coletivo plural formalmente constituído dentro da universidade com o propósito de criar meios favoráveis à realização da política.

O artigo de Layla Teixeira Cesar trata da experiência do Mestrado em Sustentabilidade junto a Povos e Terras Tradicionais da Universidade de Brasília (MESPT/UnB). A autora descreve como a interculturalidade, enquanto proposição pedagógica que orienta a atuação do MESPT, pode ser bloqueada por limites institucionais estabelecidos pela própria universidade. Como no caso anterior, a organização institucional do saber não se separa de certas concepções epistemológicas hegemônicas, o que não quer dizer que sejam equivalentes. É precisamente porque não o são que os limites institucionais podem ser forçados por meio de efeitos específicos extraídos da recriação de algumas práticas pedagógicas, desde uma outra compreensão sobre as dissertações, dos saberes que contam como válidos, até a composição de bancas mais plurais.

O artigo de Luiza Flores altera parcialmente a ênfase e nos permite compreender uma experiência de encontro de saberes a partir da perspectiva das mulheres negras da Comunidade Kilombola Morada da Paz (Triunfo, RS), que constroem a sua relação com a universidade por meio da diferença que traçam entre o "saber", vinculado a vivências comunitárias, e o "conhecer", associado às práticas epistemológicas mais distanciadas que seriam características do meio acadêmico. Poderíamos dizer que o encontro de saberes, que nomeia como "saber" todos os lados que entram em relação, é renomeado como um encontro entre práticas de "saber" e práticas de "conhecer". Essa diferença torna sensível a ideia de "borda", uma ideia muito importante para a comunidade, e confere uma dimensão ecológica à conexão parcial criada com a universidade. Nos processos ecológicos, como escreve a autora, a palavra "borda nomeia as zonas fronteiriças entre dois ecossistemas". As mulheres da comunidade não se recusam a estabelecer relações com a universidade, mas o fazem redefinindo o seu sentido, selecionando no meio acadêmico tudo aquilo que sentem como capaz de fortalecer o seu próprio modo de existência. Trata-se de capturar no "conhecer" o que pode ser retomado para o "saber". Nomear o encontro como borda é uma maneira de afirmar a fronteira como o lugar no qual uma conexão pode acontecer.

Amilton Pelegrino de Mattos, no artigo subsequente, trata dos trabalhos de pesquisa produzidos pelos estudantes indígenas da habilitação Linguagens e Artes do curso de Licenciatura Indígena da Universidade Federal do Acre. O autor descreve a conexão entre diferentes concepções de linguagem na própria escrita das pesquisas indígenas e da qual resulta a elaboração de uma ideia mais plural sobre o que é um texto, como funciona, o que ele faz e com quais forças compõe a sua existência. Essas pesquisas se apropriam de práticas 
científicas e as colocam à prova de outros regimes de signos. Práticas de linguagem como rituais, cantos e mitos passam da condição de objeto para a própria forma da pesquisa. É o que o autor chama de "coplanaridade": não se trata apenas, nem principalmente, de registrar um canto, mas de afirmar o canto como pesquisa. Não se escreve exatamente sobre um ritual, pois é o ritual que passa a ser reconhecido como escrita e como pesquisa. No caso de Ibã Huni Kuin, vemos como as "técnicas brancas" não são usadas para pesquisar saberes indígenas, mas são transformadas em meios para que se possa "chegar ao que ele chama de pesquisa huni kuin".

Partindo do contexto da Formação Transversal em Saberes Tradicionais da UFMG, e especificamente da experiência de registro audiovisual das aulas dos mestres e mestras que atuam nessa formação, o artigo de André Brasil, César Guimarães e Pedro Aspahan trata das questões éticas envolvidas na produção desses registros. O texto descreve a visita de uma turma de professores e estudantes da UFMG ao quilombo Namastê (Ubá, MG), liderado por Maria Luiza Marcelino, que também é zeladora de um centro umbandista e foi professora na FT Saberes Tradicionais. Este encontro teve como objetivo produzir uma criação audiovisual "duplamente partilhada", feita em parceria com a mestra e com os alunos e alunas da universidade. Nesse contexto, os autores refletem sobre como filmar mestres e mestras negros vinculados às religiões de matrizes africanas sem repetir os erros da cinematografia ocidental. Em contraposição a essa cinematografia, que buscou explicar as experiências espirituais de comunidades religiosas tradicionais a partir de uma lógica branca, colonizadora e ocidental, resultando na produção de imagens exotizantes dos rituais, eles buscam construir relações de reciprocidade no processo de registro de imagens. Os autores consideram que atualmente os mestres e mestras recusam o lugar de "objetos" de pesquisa e assumem o protagonismo de suas histórias, participando ativamente dos processos de criação fílmica.

O trabalho de Marco Antonio Poglia, Julio Souto Salom e Mestre Churrasco reflete sobre uma disciplina realizada na UFRGS que envolveu a participação do Mestre Churrasco, um dos mais antigos mestres de capoeira do Rio Grande do Sul. Aqui, a ideia de "transversalidade criativa" presente na proposta do dossiê é empregada não apenas para pensar os encontros realizados durante essa disciplina, mas também a composição do próprio texto, escrito em co-autoria com o mestre. Eles organizam a descrição com base em cinco tópicos, que foram eixos importantes nas aulas que Mestre Churrasco ministrou na UFRGS: o planetário, o mato, o livro, a roda e o berimbau. Partindo desses eixos, os autores apontam para uma possível relação entre o modo pelo qual se pensa a diferença entre os saberes tradicionais (pautados na oralidade, na corporalidade e na experiência) e os saberes acadêmicos (baseados principalmente na escrita) e a maneira como Bispo dos Santos (2019) distingue os saberes "orgânicos" e os saberes "sintéticos". Eles também argumentam que a 
experiência da disciplina, ainda que breve, "expressa muitos dos 'fundamentos' da capoeira para a relação com a diferença". Vemos, assim, que o "Mestre Churrasco conduziu esse encontro com a universidade como um jogo de capoeira, envolvendo os estudantes em suas brincadeiras, desestabilizando certezas e embaralhando fronteiras".

Já o texto de Geórgia Garcia está baseado em um encontro gerado pelas políticas de ações afirmativas para ingresso no ensino superior, especificamente aquelas voltadas para indígenas. Ela se propõe a pensar sobre as ações afirmativas "desde uma perspectiva do encontro de diferentes ciências, especificamente a antropologia da aprendizagem e a ciência kaingang", que "possui uma episteme organizada em noções duais de conhecimento, embasada nas marcas clânicas Kamê e Kanhru". Dialogando com o conceito kaingang de êg jykre, que de acordo com o kujá ("pajé") Pedro pode ser traduzido como "pensamento em conjunto", ou ainda como "conhecimento em conjunto", segundo Douglas Kaingang, estudante de mestrado em antropologia na UFRGS, Garcia sugere pensar o conceito de aprendizagem como "transformação", entendida como um processo que acontece ao longo de toda a vida. Um aspecto importante do trabalho é chamar a atenção para a relação entre educação e território entre os Kaingang, ressaltando que "não há como pensar em educação sem pensar em território". Nesse sentido, a autora argumenta que "o movimento entre os diferentes territórios e a própria retomada destes são essenciais ao aprendizado". Nessa perspectiva, ela considera que "é necessário ampliar as noções de território indígena para além das terras demarcadas, considerando terra indígena todos aqueles espaços em que os indígenas estão", incluindo, por exemplo, as universidades.

Voltando para as experiências de inclusão dos mestres e mestras dos saberes tradicionais como professores(as) nas universidades, o texto de Samira Lima da Costa, Eleonora Gabriel, Daniel Camargo, Karen Joyce Aragão e Sandra Benites toma como base a primeira disciplina do encontro de saberes ministrada na UFRJ, em 2019, por um conjunto de mestres e mestras guarani mbya. As autoras e autores destacam as convergências e divergências entre conhecimentos acadêmicos e saberes dos mestres e mestras guarani, incluindo as tensões entre o modelo conservador e grafocêntrico do conhecimento presente nas universidades e a transmissão do conhecimento pela oralidade e pela vivência cotidiana, que muitas vezes caracteriza os saberes tradicionais. Elas afirmam que nem sempre o "lugar de construir conhecimentos através da prática" ou de "aprender fazendo" presente nessas aulas encontra acolhimento na estrutura da universidade. Como também mencionamos acima, essas questões levantam a "necessidade de adequação das universidades, tanto no que diz respeito à oferta de novos espaços quanto de reconhecimento de diferentes temporalidades". Somado a isso, vemos que determinados elementos da cultura guarani são intraduzíveis no contexto dos espaços universitários, o que levanta uma reflexão importante sobre incomensurabilidade e limites entre diferentes modelos de conhecimentos ou 
diferentes ontologias. Tendo este aspecto em vista, as autoras e autores sugerem que o encontro de saberes deve se constituir como um "movimento de duplo sentido", envolvendo a ida dos mestres e mestras para as universidades, mas também dos alunos(as) e professores(as) até os territórios tradicionais.

O texto de Renata Marquez se propõe a pensar sobre "o papel de professora anfitriã e as reversibilidades, simetrias e colaborações implicadas" a partir de três episódios específicos, ligados direta ou indiretamente à experiência da FT Saberes Tradicionais: uma pergunta equivocada, uma proposição bibliográfica e uma proposição expográfica. O primeiro episódio traz o tema do equívoco e da "alteridade do que nomeamos como arte", apontando para questionamentos de definições universais sobre a arte. O segundo levanta novamente a questão da oralidade e da escrita, que não por acaso atravessa vários dos artigos reunidos no presente dossiê. Neste caso, a "proposição gráfica" está ligada à publicação das narrativas dos mestres e mestras dos saberes tradicionais para que possam ser usadas como referências bibliográficas, num movimento de "ampliar a rede de histórias, escritores, leitores e espectadores outros". Entretanto, Marquez observa que essa reflexão envolve também um debate sobre as limitações da escrita, "diante da presença multissensorial do discurso e do sentido das mestras e dos mestres". Como o primeiro, o terceiro episódio, a "proposição expográfica", está relacionado à reflexão sobre a arte, especificamente ao questionamento da dicotomia moderna entre "arte" e "artesanato". Trata-se de pensar as exposições em espaços museológicos e afins chamando a atenção para o "gesto urgente de ocupar os circuitos culturais com outras epistemologias". Os três episódios falam sobre os encontros entre diferentes "disciplinas anfitriãs" - a arte, o design, a arquitetura e a antropologia - e os saberes tradicionais. Nesse contexto, a proposta do trabalho é refletir sobre "certas práticas de aliança que se desdobram a partir do encontro com esses campos móveis", em diálogo com a reflexão crítica da antropologia sobre encontros com "outros".

Fechando este primeiro conjunto de textos, o artigo de Marinho Rodrigues e de Marcio Goldman, publicado na seção espaço aberto, dedica-se a pensar diante dos próprios efeitos do encontro entre eles e das possibilidades criadas pela conexão entre os meios diferentes aos quais estão vinculados. O texto é o resultado de uma conversa pública entre os dois, da qual participam, com perguntas e observações, colegas que também estão engajados em experiências de encontros entre saberes. Em uma dessas intervenções, nossa colega Cynthia Barra formula a questão que talvez seja uma das principais da conversa: "como se dá um bom encontro?". Na medida em que há um encontro, em que há uma aposta no sentido de que algo bom pode acontecer a partir dessa relação, a resposta para essa questão só pode vir daquilo que o próprio encontro torna possível. Não existe resposta geral para essa pergunta. Os autores demonstram que o seu encontro - que naquele momento já 
datava de 20 anos - foi importante, absolutamente vital, para os dois, mas que o sentido dessa importância não coincide para cada um deles. Trata-se da criação de uma aprendizagem recíproca precisamente porque a reciprocidade jamais incluiu qualquer intenção de aplainar as suas respectivas diferenças. Nas palavras de Marinho: "isso foi me ajudando a criar ideias e caminhos de forma que eu pudesse também contribuir para essa coisa mais ampliada, no sentido de lançar pontes entre as comunidades tradicionais de terreiro e o campo acadêmico". Há pontes dos dois lados, ambas são capazes de produzir amizade e criação, mas nenhuma das duas precisa se pensar como situada em uma posição equidistante.

Os trabalhos reunidos neste dossiê fornecem um panorama de diferentes experiências e iniciativas que nomeamos como encontro de saberes, compreendido naquela acepção mais ampla que já mencionamos. Compondo esse conjunto, há uma diversidade que consideramos fundamental que seja mantida e enfatizada. É exatamente essa heterogeneidade que nos permite reconhecer a existência de algumas questões transversais. Uma delas diz respeito aos limites institucionais e burocráticos impostos pela própria estrutura da universidade, os quais se refletem em uma série de aspectos práticos como o financiamento dessas iniciativas (ou a falta de verba para mantê-las); as dificuldades em remunerar os mestres e as mestras; os espaços nos quais as aulas acontecem e suas implicações; as diferentes temporalidades; como lidar com a frequência e a avaliação das disciplinas, e assim por diante.

Na relação com o problema relativo aos modos de transmissão do conhecimento, especialmente pelo contraste entre os saberes sintéticos e os saberes orgânicos, emerge também a questão da conexão entre a oralidade e a escrita, com todas as possibilidades e dificuldades colocadas pela confluência entre ambas. Nesse sentido, alguns dos trabalhos sugerem que as diferentes experiências de encontros de saberes possibilitam composições entre a escrita e a oralidade, bem como aberturas para outros tipos de narratividade (fotografias, vídeos, cantos, danças, arte, poesias, exposições, e assim por diante).

Reforçamos ainda, e mais uma vez, a questão relativa aos riscos implicados em todas essas experiências, e àqueles mencionados anteriormente poderíamos acrescentar o da tolerância. Mesmo nas iniciativas que visam a inclusão, como sugere Layla Teixeira Cesar, muitas vezes os saberes tradicionais são vistos como complementares aos conhecimentos científicos e levados em consideração apenas na medida em que se apresentam, de alguma forma, como compatíveis com uma certa lógica ocidental ou com princípios epistemológicos nos quais a universidade se reconhece com mais facilidade. Aqui, como alhures, todo ato de criação cria também os seus próprios riscos.

Pensamos que a publicação de um dossiê com textos que apresentam testemunhos tão expressivos de algumas das intervenções mais interessantes que estão acontecendo nos 
últimos anos dentro do meio acadêmico, cria também a ocasião para reconhecermos outros possíveis para a universidade. Resistir à escalada autoritária e negacionista em curso é sobretudo afirmar outras coisas, um dos únicos modos de não ceder ao medo e ao ressentimento, os dois venenos de cuja aliança sempre resultam efeitos mortíferos. 0 encontro de saberes é possível porque todos esses coletivos negros, indígenas, tradicionais sempre souberam afirmar os seus vários modos de existência diante de todas as investidas colonialistas, racistas, capitalistas que tentaram, e ainda tentam destrui-los, assimilando-os à tristeza, que é a negação de sua imagem. Nas palavras de Marinho Rodrigues: "a gente sempre pensou, mas do nosso jeito, e respeitamos o jeito das outras pessoas pensarem".

\section{REFERÊNCIAS}

BISPO DOS SANTOS, Antonio. "As fronteiras entre o saber orgânico e o saber sintético". In: OLIVA, Anderson Ribeiro; MARONA, Marjorie Corrêa; FILICE, Renísia Cristina Garcia (Org.). Tecendo redes antirracistas: Áfricas, Brasis, Portugal. Belo Horizonte: Autêntica, 2019.

PIGNARRE, Philippe; STENGERS, Isabelle. La sorcellerie capitaliste. Pratiques de désenvoutement. Paris: La Découverte, 2005.

SILVA, Ana Claudia Matos (Ana Mumbuca). Uma escrita contra-colonialista do Quilombo Mumbuca Jalapão-TO. Universidade de Brasília - Mestrado em Sustentabilidade junto a Povos e Territórios Tradicionais. Dissertação de Mestrado, 2019.

STENGERS, Isabelle. Cosmopolitiques. Paris: Editions La Découverte, 2003.

p. 183-196, 2005. Introductory notes on an ecology of practices. Cultural Studies Review, v.11, n. 11, Reativar 0 animismo. Chão da Feira/ Cadernos de Leituras, n. 62, 2017.

VIÈLE, Anne. "Postface. Puissance et générosité de l'art du 'faire attention'". In: PIGNARRE, Philippe; STENGERS, Isabelle. La sorcellerie capitaliste. Pratiques de désenvoutement, 199-225. Paris: La Découverte, 2005. p. 199-225. 